\title{
SEXUAL BEHAVIOR AND SEXUAL DYSFUNCTIONS AFTER AGE 40: THE GLOBAL STUDY OF SEXUAL ATTITUDES AND BEHAVIORS
}

\author{
ALFREDO NICOLOSI, EDWARD O. LAUMANN, DALE B. GLASSER, \\ EDSON D. MOREIRA, JR, ANTHONY PAIK, AND CLIVE GINGELL, FOR THE GLOBAL STUDY OF \\ SEXUAL ATTITUDES AND BEHAVIORS INVESTIGATORS' GROUP
}

\begin{abstract}
Objectives. To assess the importance of sex and the prevalence of sexual dysfunction among middle-aged and older adults throughout the world. Increasing life expectancy has been accompanied by improvements in the health of the middle-aged and elderly, but little is known about how this has affected their sexual experience.

Methods. Data were collected in 29 countries from 27,500 men and women aged 40 to 80 years using a standardized questionnaire (self-completed or by interview). Sexual dysfunction was defined as frequent and persistent problems. They included early ejaculation and erectile difficulties in men, lubrication difficulties and pain during intercourse in women, and a lack of sexual interest, an inability to achieve orgasm, and a feeling of unpleasurable sex in both.

Results. More than $80 \%$ of the men and $65 \%$ of the women had had sexual intercourse during the past year. Of these subjects, the most common dysfunctions were early ejaculation (14\%) and erectile difficulties (10\%) among the men and a lack of sexual interest (21\%), inability to reach orgasm (16\%), and lubrication difficulties (16\%) among the women. Overall, $28 \%$ of the men and 39\% of the women said that they were affected by at least one sexual dysfunction.

Conclusions. The results of our study indicate that sexual desire and activity are widespread among middle-aged and elderly men and women worldwide and persist into old age. The prevalence of sexual dysfunctions was quite high and tended to increase with age, especially in men. Although major betweencountry differences were noted, this global study revealed some clear and consistent patterns. UROLOGY 64: 991-997, 2004. (c) 2004 Elsevier Inc.
\end{abstract}

$\mathbf{I}_{\mathrm{b}}^{\mathrm{n}}$ ncreasing life expectancy has been accompanied by improvements in the health and quality of life (QOL) of the middle-aged and elderly, but little is

The Global Study of Sexual Attitudes and Behaviors was funded by Pfizer Inc.

From the Department of Epidemiology, Institute of Biomedical Technologies, National Research Council, Milan, Italy; G. H. Sergievsky Center, Columbia University School of Public Health, New York, New York; Department of Sociology, University of Chicago, Chicago, Illinois; Pfizer Inc, New York, New York; Gonçalo Moniz Research Center, Oswaldo Cruz Foundation, Salvador, Brazil; University of Iowa, Salt Lake City, Iowa; and Bristol Urological Institute, Southmead Hospital, Bristol, United Kingdom

Reprint requests: Alfredo Nicolosi, M.D., Ph.D., Department of Epidemiology, Institute of Biomedical Technologies, National Research Council, Via Fratelli Cervi 93, Segrate, Milan 20090, Italy

Submitted: March 22, 2004, accepted (with revisions) June 21, 2004 known about how this change has affected their sexual experience. The few studies that have examined sexuality among middle-aged and older adults have reported that their interest in sex persists. ${ }^{1-4}$

Some studies have considered the prevalence of sexual problems among the middle-aged and elderly people, but only a few were based on population samples and collected information concerning different problems. ${ }^{5}$ Also, these studies mainly involved U.S. and Western European populations. ${ }^{6-10}$ Several studies of the prevalence of, and risk factors for, erectile dysfunction (ED) have been done, ${ }^{11-14}$ and some have studied early (or "premature") ejaculation at the population level. ${ }^{13-15}$ Additionally, a few studies have recently explored the challenging field of female sexual problems. ${ }^{16-18}$

The aim of our study was to assess the impor- 
tance of sex for individuals and their relationships, and the frequency of sexual problems among women and men aged 40 to 80 years in many of the world's regions.

\section{MATERIAL AND METHODS}

The Global Study of Sexual Attitudes and Behaviors was carried out during 2001 and 2002 in 29 countries.

\section{SAMpling ANd Data Collection}

The data were collected using the most effective survey method in each country. A random-digit-dialing sampling design was used in Europe, Israel, North America, Brazil, Australia, and New Zealand, with the respondents randomly selected within households by asking for the man or woman aged 40 to 80 years who had had the most recent birthday, and the interviews were conducted by telephone. Because of a bias against telephone interviews among the lower income groups, a mix of telephone and in-person interviews was used in Mexico.

In the Middle East and South Africa, a door-to-door protocol was used. The homes were selected using a random starting point, and the interviewers contacted every third house. The respondents self-completed a questionnaire and returned it to the interviewer. In Asian countries, other than Japan, we used an intercept method (rural areas were not included because of logistical problems). The individuals were randomly contacted in public areas by an interviewer who asked them to self-complete a questionnaire. In Japan, names were randomly selected from the national telephone database, and those people were mailed a questionnaire with a postage-paid return envelope and an incentive check of 4 U.S. dollars.

Regardless of the sampling method, the respondents were contacted by same-gender interviewers (not applicable in Japan).

\section{Questionnaire and Definitions}

The questionnaire included questions on demographics, health, relationships, sexual behavior, attitudes, and beliefs. It was developed in English, translated into the native languages, and then translated back into English to confirm that the questions were exactly the same in all of the languages in which it was administered.

The presence of sexual dysfunctions was assessed using two sequential questions. The respondents were first asked whether they had ever experienced one or more sexual problems (for men and women: lack of interest in sex, inability to achieve orgasm, sex not pleasurable; for men: early ejaculation and erection difficulties; and for women: lubrication difficulties and pain during intercourse) for a period of 2 months or more during the previous year. Those who answered positively were asked to specify the frequency of the problem as "occasionally," "sometimes," or "frequently." In calculating the prevalence of sexual dysfunctions, we excluded those individuals who reported occasional problems because the term "sexual dysfunction" implies a persistent problem.

To assess the impact of sexual dysfunctions on the QOL, we asked the question "If you were to spend the rest of your life with your sexual function the way it is today, how would you feel about this?," with the offered answers of "very satisfied," "somewhat satisfied," "neither satisfied nor dissatisfied," "somewhat dissatisfied," and "very dissatisfied."

The categorization of household income as "low," "medium," or "high" was based on the distribution of income in each country to make it possible to compare nations with different absolute mean incomes.

Religious affiliations were categorized as "Christian/Jew,"
"Muslim," "Buddhist or other Asian" (which included Confucians, Animists, Spiritists, Hindus, and Taoists), "atheist," and "other," which included less frequently mentioned religions.

\section{Statistical Analysis}

The countries were grouped into clusters, taking into account their geographic region, cultural background, and the method of data collection.

The denominator of the prevalence of sexual dysfunctions was the number of sexually active people (ie, at least one episode of intercourse during the previous year). The prevalence was age-standardized using the age distribution of each gender in the entire study population, ${ }^{19}$ which closely corresponded to the 2001 U.S. population aged 40 to 79 years. Confidence intervals were used to compare the prevalence of sexual dysfunctions in the country clusters. ${ }^{20}$

The association between the method of administering the questionnaire (ie, telephone interview versus self-completed) and the likelihood of reporting sexual problems was estimated using logistic regression analysis adjusted for gender, age, country, education, and income. ${ }^{21}$ Partial correlation analysis ${ }^{19}$ was used to examine the correlation between the frequency of experiencing sexual problems and the subjects' reported degree of sexual satisfaction (QOL), controlling for age, sex, and country.

\section{RESULTS}

Overall, 191,310 individuals were contacted, of whom 45,930 were not eligible to participate. Of the 145,380 eligible individuals, 97,462 refused to participate at the introduction, and 21,598 interrupted the interview. A total of 27,516 individuals completed the questionnaire, for a response rate of $19 \%$ (29.7\% in the countries in which the sampling involved direct personal contact, $15.3 \%$ in the countries in which the interview was administered by telephone, and 33.3\% in Japan).

\section{Demographic and Social CHARACTERISTICS}

The East Asian cluster had the greatest proportion of individuals who were married or involved in an ongoing partnership (Table I). The greater proportion of nonurban respondents in the European and non-European Western clusters was a result of the sampling, which excluded rural areas in Asian countries and Turkey. Non-European Western and Northern European residents had the greatest educational level. The respondents predominantly fell in the middle or lower income categories, although the highest level was also represented. Most of the respondents in Europe and the Americas were Christian or Jewish; most in the Middle East were Muslim; and most Asian respondents claimed an affiliation with Buddhism or another Asian religion, although a substantial proportion were Christians, members of other religions, and atheists.

\section{Sexual Activity, Attitudes, and Beliefs}

More than $80 \%$ of the men and $65 \%$ of the women reported that they had had sexual intercourse during the 12 months preceding the inter- 
TABLE I. Subject characteristics

\begin{tabular}{|c|c|c|c|c|c|c|c|c|c|c|c|c|c|c|}
\hline \multirow[b]{2}{*}{ Characteristic } & \multicolumn{2}{|c|}{ Northern Europe } & \multicolumn{2}{|c|}{ Southern Europe } & \multicolumn{2}{|c|}{$\begin{array}{c}\text { Non-European } \\
\text { West }\end{array}$} & \multicolumn{2}{|c|}{$\begin{array}{c}\text { Central/South } \\
\text { America }\end{array}$} & \multicolumn{2}{|c|}{ Middle East } & \multicolumn{2}{|c|}{ East Asia } & \multicolumn{2}{|c|}{ South East Asia } \\
\hline & $\mathbf{M}$ & $\mathbf{W}$ & $\mathbf{M}$ & $\mathbf{W}$ & $\mathbf{M}$ & $\mathbf{W}$ & M & $\mathbf{W}$ & M & W & $\mathbf{M}$ & $\mathbf{W}$ & M & W \\
\hline Sample size (n) & 2727 & 2773 & 2502 & 2503 & 2745 & 2752 & 723 & 982 & 1571 & 1522 & 2100 & 2100 & 1250 & 1250 \\
\hline Mean age $(y r)$ & $57(11)$ & $58(11)$ & $56(12)$ & $56(11)$ & $55(11)$ & $55(11)$ & $56(11)$ & $55(11)$ & $54(10)$ & $54(10)$ & $56(11)$ & $54(11)$ & $53(10)$ & $53(10)$ \\
\hline $\begin{array}{l}\text { Married or ongoing } \\
\text { partnership }\end{array}$ & 77.9 & 69.8 & 85.6 & 77.4 & 77.0 & 68.1 & 87.1 & 63.0 & 86.9 & 69.7 & 94.7 & 82.9 & 85.2 & 70.4 \\
\hline Urban residence & 68.3 & 68.8 & 82.0 & 76.2 & 77.1 & 76.0 & 93.6 & 96.4 & 89.1 & 88.7 & 92.4 & 90.9 & 99.4 & 98.7 \\
\hline \multicolumn{15}{|l|}{ Education } \\
\hline Primary school or less & 10.8 & 12.3 & 34.8 & 47.3 & 15.3 & 14.2 & 28.4 & 40.7 & 33.4 & 50.9 & 15.7 & 26.0 & 16.9 & 29.8 \\
\hline Secondary/high school & 63.7 & 67.0 & 38.3 & 32.2 & 46.9 & 52.7 & 42.7 & 40.8 & 26.6 & 17.3 & 56.9 & 56.6 & 48.4 & 48.6 \\
\hline At least some college & 25.5 & 20.7 & 26.9 & 20.6 & 37.7 & 33.0 & 28.9 & 18.5 & 40.0 & 31.7 & 27.4 & 17.4 & 34.7 & 21.6 \\
\hline \multicolumn{15}{|l|}{ Household income } \\
\hline Low & 18.4 & 30.9 & 38.9 & 54.0 & 22.2 & 31.1 & 15.7 & 24.7 & 35.0 & 35.6 & 25.3 & 28.2 & 26.2 & 35.4 \\
\hline Medium & 55.3 & 49.8 & 47.3 & 36.9 & 46.0 & 44.4 & 72.7 & 69.2 & 53.9 & 51.5 & 53.8 & 51.8 & 56.6 & 48.0 \\
\hline High & 26.3 & 19.3 & 13.8 & 9.1 & 31.7 & 24.5 & 11.6 & 6.1 & 11.0 & 12.9 & 20.9 & 19.9 & 17.2 & 16.6 \\
\hline Currently employed & 58.1 & 58.9 & 58.5 & 71.2 & 61.3 & 62.5 & 66.6 & 79.2 & 63.9 & 78.5 & 67.7 & 82.3 & 73.0 & 86.2 \\
\hline \multicolumn{15}{|l|}{ Religion } \\
\hline Christian/Jew & 76.9 & 84.1 & 83.8 & 92.1 & 84.1 & 88.2 & 89.9 & 89.7 & 2.3 & 1.7 & 15.6 & 21.1 & 29.8 & 26.9 \\
\hline Muslim & 1.5 & 0.5 & 1.3 & 0.4 & 1.1 & 0.6 & 0.1 & 0.0 & 96.6 & 97.8 & 0.2 & 0.3 & 26.9 & 25.5 \\
\hline Buddhist or other Asian & 0.4 & 0.3 & 0.0 & 0.1 & 0.5 & 0.4 & 0.0 & 0.0 & 0.0 & 0.0 & 37.0 & 42.6 & 38.8 & 42.5 \\
\hline Atheist & 14.8 & 10.7 & 6.7 & 4.6 & 5.7 & 3.4 & 0.9 & 0.4 & 2.1 & 0.9 & 33.8 & 27.5 & 0.2 & 0.0 \\
\hline Other & 6.4 & 4.4 & 8.2 & 2.9 & 8.6 & 7.5 & 4.9 & 7.7 & 3.1 & 1.7 & 13.5 & 8.5 & 4.4 & 5.1 \\
\hline $\begin{array}{l}\text { Good to excellent general } \\
\text { health }\end{array}$ & 72.8 & 69.5 & 70.1 & 59.6 & 77.8 & 75.4 & 70.6 & 55.8 & 71.7 & 50.4 & 63.0 & 53.1 & 69.1 & 61.2 \\
\hline Hypertension & 21.1 & 21.8 & 25.5 & 29.6 & 18.5 & 26.3 & 23.4 & 31.7 & 24.4 & 34.7 & 24.8 & 22.9 & 20.8 & 19.6 \\
\hline Diabetes & 8.3 & 6.1 & 9.8 & 8.0 & 9.5 & 10.2 & 8.9 & 9.2 & 16.1 & 17.1 & 13.6 & 11.7 & 11.9 & 8.3 \\
\hline Intercourse in last $12 \mathrm{mo}$ & 81.1 & 68.4 & 88.4 & 72.8 & 81.2 & 67.1 & 88.5 & 60.6 & 84.3 & 61.4 & 84.7 & 67.1 & 74.5 & 51.1 \\
\hline $\begin{array}{l}\text { Intercourse more than } \\
\text { once a week }\end{array}$ & 42.2 & 37.4 & 56.2 & 47.3 & 44.5 & 36.7 & 50.5 & 37.1 & 47.6 & 29.8 & 20.2 & 10.7 & 33.4 & 27.1 \\
\hline
\end{tabular}

KEY: $M=$ men; $W=$ women.

Data presented as percentages, unless otherwise noted; data in parentheses are standard deviations.

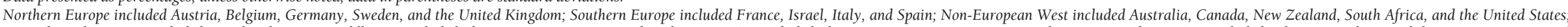

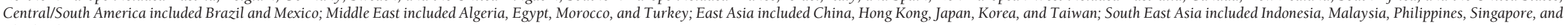
Thailand. 
view. Among the men, this proportion was 93\% in the 40 to 49 -year-age group and 53\% in the group aged 70 to 80 years; among the women, the corresponding figures were $88 \%$ and $21 \%$. Forty-four percent of the men and $38 \%$ of the women engaged in sexual intercourse more than once a week, with differences between the country clusters.

When asked to agree or disagree with a number of statements, $82 \%$ of the men and $76 \%$ of the women agreed that "satisfactory sex is essential to maintain a relationship." The corresponding proportions were $17 \%$ and $23 \%$ for the statement "older people no longer want sex," but these were higher in developing countries. Finally, $68 \%$ of the men and $60 \%$ of the women declared that they were "in favor of the use of medical treatments to help older people enjoy sexual activity"; the degree of consent was lower in developing countries.

\section{Prevalence of Sexual Dysfunctions}

Early ejaculation was the most commonly reported dysfunction in men and was more frequently reported in the Asian, Central/South American, and non-European Western clusters (Table II). Erectile difficulties were the second most frequent dysfunction, with greater rates in the Asian countries. Overall, 28\% of the men reported having at least one of the considered dysfunctions, but this proportion was greater in Asia. The prevalence of ED greatly increased with age and was the most frequent disorder among the oldest men (Fig. 1). The pattern of a lack of sexual interest and an inability to reach orgasm was similar to that of ED.

A lack of sexual interest was the most common sexual problem among women, with greater rates in Southeast Asia and the Middle East. The inability to reach orgasm was the second most frequent problem, with the greatest prevalence in Asia and the lowest in Northern Europe. Not finding sex pleasurable followed the same pattern. Lubrication difficulties were reported by $16 \%$ of the women and were more prevalent in Asia. Overall, 39\% reported having at least one of the studied dysfunctions, with greater proportions in Asia and the Middle East. The age pattern of sexual dysfunctions was more marked among the men than among the women (Fig. 2).

The frequency of experiencing a sexual problem correlated inversely with the degree of satisfaction with sexual life (QOL) among both men and women $(P<0.0001)$. Logistic regression analyses found that the method of administering the questionnaire had no statistically significant effect on the likelihood of reporting any specific sexual problem.

\section{COMMENT}

The Global Study of Sexual Attitudes and Behaviors is the first multinational survey of sex and relationships among middle-aged and older people and revealed the prevalence of the conditions impairing sexual health at these ages.

Because of its global nature, the study had to deal with a number of methodologic problems. The sample population in each country was not a truly random sample of the entire population. A fully random sample of the population of 29 countries would hardly be feasible with limited resources, whereas focusing on selected areas can provide initial estimates. The sampling method in each country was chosen to ensure the widest population coverage.

We did not use face-to-face interviews because these could embarrass people when talking about private issues. ${ }^{22}$ The overall response rate was not high, but was greater in the countries in which the offer of participation involved personal contact. People are reluctant to refuse a personal contact, but are more at ease in declining if the request was made by an anonymous caller at the other end of a telephone line. ${ }^{23}$ Previous studies have shown that the difference between in-person interviews and self-completed or mailed questionnaires does not affect the estimates of the prevalence of sexual behavior. ${ }^{24-26}$ Consistently, we found that the likelihood of reporting sexual problems was not influenced by the method of administering the questionnaire.

The prevalences of hypertension and diabetes were consistent with the available age-specific and gender-specific regional figures. ${ }^{27,28}$ This is an indication that our sampling design did not introduce selection bias. We assume that the main reason for refusal was a generic unavailability to participate in a survey ( $67 \%$ of the contacts refused participation at introduction, and if they were excluded, the response rate would be 57\%).

We considered sexual dysfunctions to be only those sexual problems that were persistent and at least moderately frequent. ${ }^{29}$ It is likely that their prevalence was underreported, because the method we used minimized the false-positive rate. We found a strong correlation between the frequency of sexual problems and the dissatisfaction they generate. This adds to the validity of the results, because the subjective feeling about a sexual problem plays a major role in making it a dysfunction.

It is difficult to compare our results with those of previous studies because few of them were based on population samples, many included individuals younger than 40 years old, and their definitions of sexual problems were often different. However, 
TABLE II. Age-standardized prevalence of sexual dysfunctions by country cluster for sexually active subjects

\begin{tabular}{|c|c|c|c|c|c|c|c|c|}
\hline Sexual Dysfunction & $\begin{array}{c}\text { Northern } \\
\text { Europe }\end{array}$ & $\begin{array}{c}\text { Southern } \\
\text { Europe }\end{array}$ & $\begin{array}{l}\text { Non- } \\
\text { European } \\
\text { West }\end{array}$ & $\begin{array}{l}\text { Central/ } \\
\text { South } \\
\text { America }\end{array}$ & $\begin{array}{c}\text { Middle } \\
\text { East }\end{array}$ & East Asia & $\begin{array}{c}\text { South } \\
\text { East Asia }\end{array}$ & Total \\
\hline \multicolumn{9}{|l|}{ Men } \\
\hline Early ejaculation & $10(9-11)$ & $13(12-15)$ & $16(14-17)$ & $22(19-25)$ & $8(7-10)$ & $19(17-21)$ & 25 (22-29) & $14(14-15)$ \\
\hline Erection difficulties & $8(7-9)$ & $8(7-9)$ & $11(10-13)$ & $9(6-11)$ & $8(6-10)$ & $15(13-17)$ & $22(18-25)$ & $10(9-10)$ \\
\hline Lack of interest in sex & $7(6-8)$ & $6(5-7)$ & $9(8-11)$ & $9(7-11)$ & $13(11-15)$ & $12(11-14)$ & $20(17-23)$ & $9(9-10)$ \\
\hline Inability to achieve orgasm & $5(4-6)$ & $7(6-8)$ & $8(7-9)$ & $8(6-11)$ & 7 (6-9) & $10(9-12)$ & $15(13-18)$ & $7(7-8)$ \\
\hline Sex not pleasurable & $4(3-5)$ & $5(4-6)$ & $6(5-7)$ & $4(3-6)$ & $8(6-10)$ & $7(6-8)$ & $12(10-15)$ & $6(5-6)$ \\
\hline At least one problem & $23(22-25)$ & $24(22-26)$ & $29(27-31)$ & $31(29-35)$ & $26(23-28)$ & $34(32-36)$ & $44(40-48)$ & $28(28-29)$ \\
\hline \multicolumn{9}{|l|}{ Women } \\
\hline Lack of interest in sex & 17 (15-19) & $21(19-23)$ & $19(17-21)$ & $20(16-24)$ & $29(24-34)$ & $27(25-30)$ & $34(28-39)$ & $21(20-22)$ \\
\hline Inability to achieve orgasm & $10(9-12)$ & $17(15-19)$ & $16(14-17)$ & $16(13-19)$ & $17(12-21)$ & $23(21-26)$ & 34 (29-39) & $16(15-17)$ \\
\hline Lubrication difficulties & $13(11-14)$ & $12(10-14)$ & $19(17-21)$ & $18(15-22)$ & $12(8-16)$ & $28(25-30)$ & $28(23-33)$ & $16(15-16)$ \\
\hline Sex not pleasurable & $10(8-11)$ & $15(13-17)$ & $12(10-14)$ & $14(11-17)$ & $22(17-26)$ & $21(17-24)$ & $28(23-33)$ & $15(14-15)$ \\
\hline Pain during sexual intercourse & $5(4-7)$ & $8(7-10)$ & $8(7-9)$ & $14(11-17)$ & $14(10-19)$ & $20(18-23)$ & $22(17-27)$ & $10(10-11)$ \\
\hline At least one problem & $31(29-33)$ & $36(33-38)$ & $38(35-40)$ & $38(34-42)$ & $46(42-51)$ & $47(44-50)$ & $55(50-61)$ & $39(38-40)$ \\
\hline
\end{tabular}

Data presented as percentage, with $95 \%$ confidence interval in parentheses.

Countries included in country clusters same as noted for Table I. 


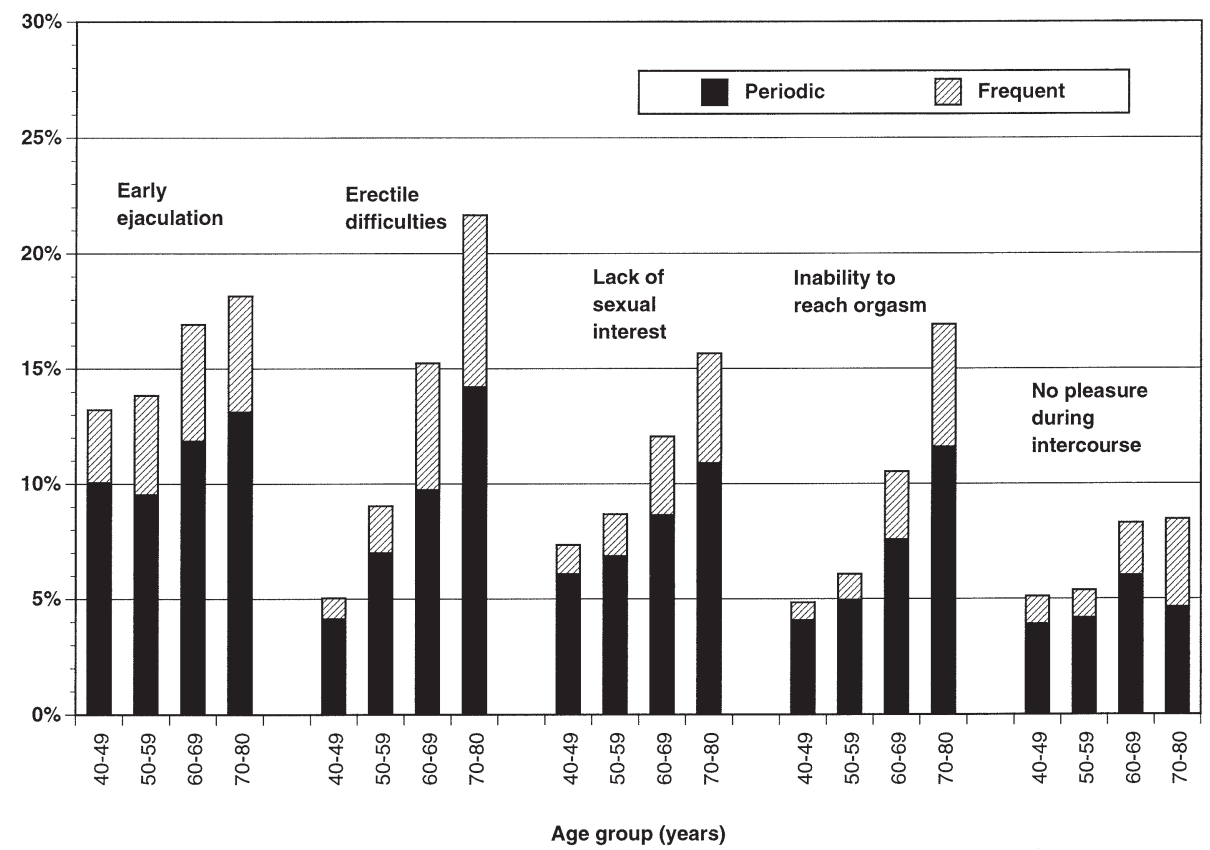

FIGURE 1. Prevalence of specific sexual dysfunctions in the male population of Global Study of Sexual Attitudes and Behaviors, 2001 to 2002 ("periodic" and "frequent" sexual problems among sexually active men).

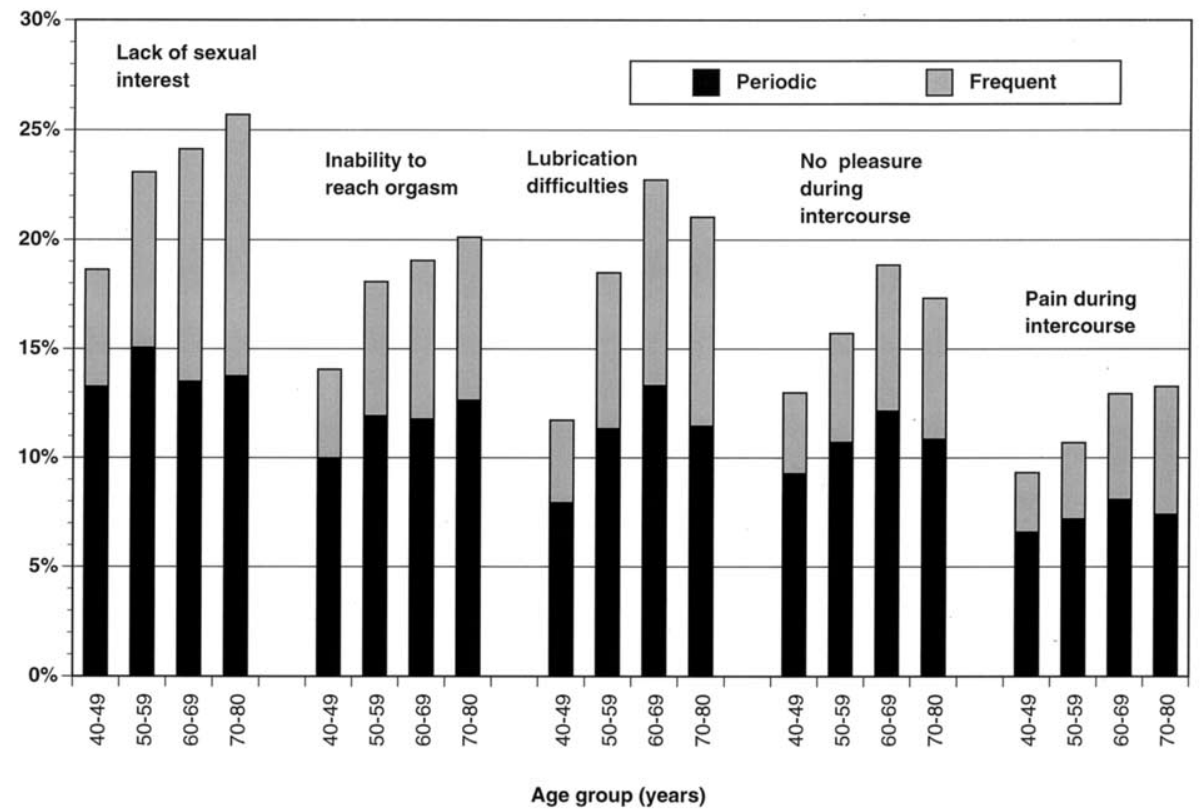

FIGURE 2. Prevalence of specific sexual dysfunctions in the female population of Global Study of Sexual Attitudes and Behaviors, 2001 to 2002 ("periodic" and "frequent" sexual problems among sexually active women).

our findings are consistent with those reported by previous population studies of the prevalence of ED, ${ }^{11-13}$ even if our estimates are slightly lower, because we used a more specific screening method. The prevalence of early ejaculation $^{9,11,13-15}$ in men and other sexual dysfunctions in women ${ }^{5,6,8-10,16-18}$ reported in the few other population studies carried out in various parts of the world is generally consistent with that of the region-specific prevalence found by us.

\section{CONCLUSIONS}

The findings of our study have shown that sexual desire and activity are widespread among middleaged and elderly men and women worldwide and persist into old age. A substantial proportion indicated that sexual activity is essential for self-esteem and to maintain a relationship and would like to remain sexually active. The prevalence of sexual dysfunctions is quite high and tends to increase 
with age, especially in men. Although major between-country differences were found, this global study revealed some clear and consistent patterns.

Acknowledgment. To our colleagues on the Global Study of Sexual Attitudes and Behaviors' International Advisory Board: Gerald Brock (Canada), Jacques Buvat (France), Uwe Hartmann (Germany), Sae-Chul Kim (Korea), Rosie King (Australia), Bernard Levinson (South Africa), Ken Marumo (Japan), and Ferruh Simsek (Turkey) for their contribution.

\section{REFERENCES}

1. Diokno AC, Brown MB, and Herzog AR: Sexual function in the elderly. Arch Intern Med 150: 197-200, 1990.

2. Deacon S, Minichiello V, and Plummer D: Sexuality and older people: revisiting the assumptions. Educ Gerontol 21: 497-513, 1995

3. Matthias RE, Lubben JE, Atchison KA, et al: Sexual activity and satisfaction among very old adults: results from a community-dwelling Medicare population survey. Gerontologist 37: 6-14, 1997.

4. Gott M, and Hinchliff S: How important is sex in later life? The views of older people. Soc Sci Med 56: 1617-1628, 2003.

5. Simons JS, and Carey MP: Prevalence of sexual dysfunctions: results from a decade of research. Arch Sex Behav 30: 177-219, 2001.

6. Fugl-Meyer AR, and Fugl-Meyer KS: Sexual disabilities, problems and satisfaction in 18-74 year old Swedes. Scand J Sexol 2: 79-105, 1999.

7. Ventegodt S: Sex and the quality of life in Denmark. Arch Sex Behav 27: 295-307, 1998.

8. Dunn KM, Croft PR, and Hackett GI: Association of sexual problems with social, psychological, and physical problems in men and women: a cross sectional population survey. J Epidemiol Community Health 53: 144-148, 1999.

9. Laumann EO, Paik A, and Rosen R: Sexual dysfunction in the United States: prevalence and predictors. JAMA 281: 537-544, 1999

10. Richters J, Grulich AE, de Visser RO, et al: Sex in Australia: sexual difficulties in a representative sample of adults. Aust N Z J Public Health 27: 164-170, 2003.

11. Prins J, Blanker MH, Bohnen AM, et al: Prevalence of erectile dysfunction: a systematic review of population-based studies. Int J Impot Res 14: 422-432, 2002.

12. Nicolosi A, Moreira ED Jr, Shirai M, et al: Epidemiology of erectile dysfunction in four countries: cross-national study of the prevalence and correlates of erectile dysfunction. Urology 61: 201-206, 2003.

13. Blanker MH, Bosch JL, Groeneveld FP, et al: Erectile and ejaculatory dysfunction in a community-based sample of men 50 to 78 years old: prevalence, concern, and relation to sexual activity. Urology 57: 763-768, 2001.

14. Helgason AR, Adolfsson J, Dickman P, et al: Sexual desire, erection, orgasm and ejaculatory functions and their importance to elderly Swedish men: a population-based study. Age Ageing 25: 285-291, 1996.

15. Carson CC, Glasser DB, Laumann EO, et al: Prevalence and correlates of premature ejaculation among men aged 40 years and older: a United States nationwide population-based study (abstract). J Urol 169(suppl 4): 321, 2003.

16. Berman JR, Berman L, Goldstein I: Female sexual dysfunction: incidence, pathophysiology, evaluation, and treatment options. Urology 54: 385-391, 1999.

17. Anastasiadis AG, Davis AR, Ghafar MA, et al: The epidemiology and definition of female sexual disorders. World J Urol 20: 74-78, 2002.

18. Kadri N, McHichi Alami KH, and McHakra Tahiri S: Sexual dysfunction in women: population based epidemiological study. Arch Women Ment Health 5: 59-63, 2002.

19. Snedecor GW, and Cochran WG: Statistical Methods, 7th ed. Iowa University Press, Ames, Iowa, 1980.

20. Rothman KJ: A show of confidence. N Engl J Med 299: 1362-1363, 1978

21. Hosmer DW, and Lemeshow S: Applied Logistic Analysis. New York, J Wiley \& Sons, 1989.

22. ASCF Principal Investigators and Their Associates: Analysis of sexual behaviour in France (ACSF): a comparison between two modes of investigation-telephone survey and face-to-face survey. AIDS 6: 315-323, 1992.

23. Weinhardt LS, Forsyth AD, Carey MP, et al: Reliability and validity of self-report measures of HIV-related sexual behavior: progress since 1990 and recommendations for research and practice. Arch Sex Behav 27: 155-180, 1998.

24. Nebot M, Celentano DD, Burwell L, et al: AIDS and behavioural risk factors in women in inner city Baltimore: a comparison of telephone and face to face surveys. J Epidemiol Community Health 48: 412-418, 1994.

25. McEwan RT, Harrington BE, Bhopal RS, et al: Social surveys in HIV/AIDS: telling or writing? A comparison of interview and postal methods. Health Educ Res 7: 195-202, 1992.

26. Wadsworth J, Field J, Johnson AM, et al: Methodology of the National Survey of Sexual Attitudes and Lifestyles. J R Stat Soc Ser A Stat Soc 156: 407-421, 1993.

27. Kearney PM, Whelton M, Reynolds K, et al: Worldwide prevalence of hypertension: a systematic review. J Hyperten 22: 11-19, 2004.

28. King H, Aubert RE, and Herman WH: Global burden of diabetes, 1995-2025: prevalence, numerical estimates, and projections. Diabetes Care 21: 1414-1431, 1998.

29. Moynihan R: The making of a disease: female sexual dysfunction. BMJ 326: 45-47, 2003. 